\title{
The Design and Performance of 150-MW S-Band Klystrons
}

\author{
D. SPREHN, R. M. PHILLIPS, and G. CARYOTAKIS \\ MASTER \\ Stanford Linear Accelerator Center \\ Stanford University, Stanford, CA 94309
}

\section{Abstract}

As part of an international collaboration, the Stanford Linear Accelerator Center (SLAC) klystron group has designed, fabricated and tested a $60 \mathrm{~Hz}, 3 \mu \mathrm{s}, 150 \mathrm{MW}$ klystron built for Deutsches Elektronen Synchrotron (DESY). A test diode with a $535 \mathrm{kV}, 700$ A electron beam was constructed to verify the gun operation. The first klystron was built and successfully met design specifications. This paper discusses design issues and experimental results of the diode and klystron including the suppression of gun oscillations.

\section{Introduction}

The Stanford Linear Accelerator Center (SLAC) klystron group is currently designing, fabricating and testing high power klystrons which range from $477 \mathrm{MHz}$ to $11.424 \mathrm{GHz}$, and from $1 \mathrm{MW}$ under continuous operation to $150 \mathrm{MW}$ at $3 \mu \mathrm{s}$ pulsewidth. These klystrons power accelerators which are either operating, under construction, or will be used as test accelerators to study advanced concepts for future collider development.

The linear collider at SLAC uses S-band klystrons operating at $60 \mathrm{MW}$ peak output power. Due to the experience with constructing and operating hundreds of these tubes (known as $\mathbf{5 0 4 5}$ klystrons) it was decided to limit design parameters, such as gradients and cathode loading, at or below the levels of the 5045. Collector surface power dissipation, window power transmission, and rf load power levels were designated to be comparable to the 5045 klystron. Due to the high power required of the 150-MW klystrons, the cathode current, gun convergence, beam current density and voltage, focusing field, pulse energy, and the power in the output cavity will be significantly higher than found in a 5045. Some important design parameters are shown in Table 1.

\section{A 375-MW Beam Diode}

\section{A. Diode Gun Design}

Referring to Fig. 1, the cathode is supported between the focus electrode and support cup by a temperature

Work supported by the Department of Energy contract DE-AC03-76SF00515.
Table 1

Design parameters for the 150-MW klystron.

\begin{tabular}{|l|l|}
\hline Beam voltage & $535 \mathrm{kV}$ \\
\hline Beam current & $700 \mathrm{~A}$ \\
\hline RF Pulsewidth @ rep rate & $3 \mu \mathrm{s} @ 60 \mathrm{~Hz}$ \\
\hline Cathode loading & $2: 1\left(6 \mathrm{~A} / \mathrm{cm}^{2} \mathrm{max}\right)$ \\
\hline Cathode convergence & $40: 1\left(5.25^{\prime \prime}\right.$ dia. $)$ \\
\hline RF output power & $150 \mathrm{MW}$ \\
\hline Cavity gradients & $<360 \mathrm{kV} / \mathrm{cm}$ \\
\hline Saturated gain & $-55 \mathrm{~dB}$ \\
\hline Efficiency & $\geq 40 \%$ \\
\hline Operating frequency & $2998 \mathrm{MHz}$ \\
\hline Solenoidal focusing field & 2100 gauss $\left(3^{*} \mathrm{Br}\right)$ \\
\hline
\end{tabular}

compensating molybdenum and stainless steel sleeve to reduce thermal variations in the cathode-anode spacing. The focus electrode and anode housing are gently curved surfaces to provide a transmission path and alleviate the formation of trapped if modes. The focus electrode is connected to an oilcooled heat exchanger to reduce field emission. The field gradients present on the ceramic seal, corona rings, anode, and focus electrode are carefully controlled by shaping the geometry according to the results of computer simulation. Table 2 compares essential gun gradients of the 5045 and the 150-MW klystron as calculated using the electrostatic field solver POISSON (1).

The electron beam was designed using EGUN (2). In this design, the gun pole piece was outside of the vacuum

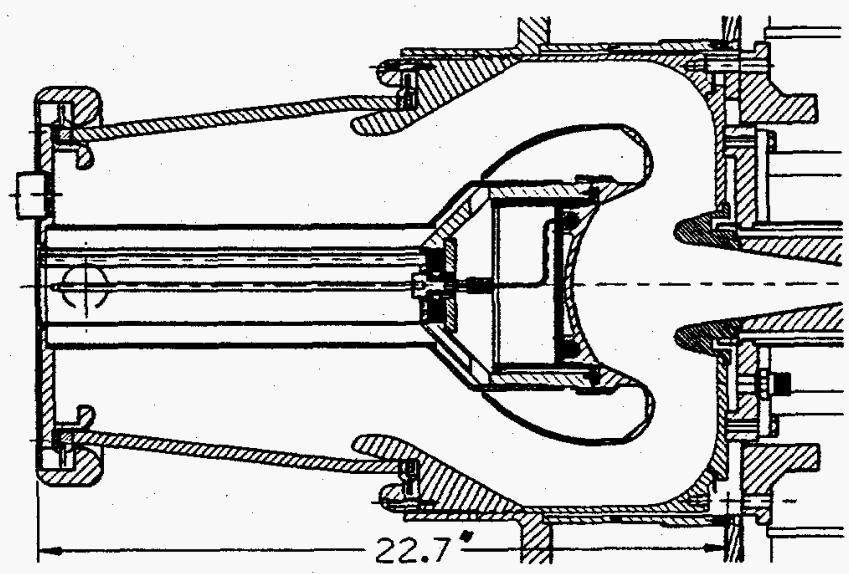

Fig. 1. Diode and 150-MW klystron gun with klystron pole piece shown. 
Table 2

Calculated gradients of the 5045 and the $150-\mathrm{MW}$ klystron guns.

\begin{tabular}{|l|c|c|}
\hline \multicolumn{1}{|c|}{ Item } & $\begin{array}{c}5045 \\
(\mathrm{kV} / \mathrm{cm})\end{array}$ & $\begin{array}{c}150-\mathrm{MW} \\
(\mathrm{kV} / \mathrm{cm})\end{array}$ \\
\hline anode nose tip & 201 & 235 \\
\hline focus electrode & 192 & 183 \\
\hline upper seal radial field & 55 & 34 \\
\hline upper seal longitudinal field & 22 & 22 \\
\hline
\end{tabular}

envelope and external to the tube body. According to simulation, beam microperveance is 1.77 at $535 \mathrm{kV}$ with a $66 \%$ filling factor and less than $8 \%$ scalloping. The klystron gun design used a slightly different pole piece having reentrancy and a larger aperture which resulted in less than $7 \%$ scalloping and a microperveance of 1.77 according to simulation.

\section{B. Diode Experimental Results}

At $3 \mu$ s operation the diode was processed to $500 \mathrm{kV}$ when rf gun oscillations were detected. Despite the oscillations, the diode was operated at full power with $3 \mu \mathrm{s}$ pulsewidth and $60 \mathrm{~Hz}$, and to $550 \mathrm{kV}$ at slightly shorter pulsewidths. The microperveance was measured at 1.78 with $99.8 \%$ beam transmission which agreed well with design.

Adjustment of the bucking or main solenoid coils produced no discernible effect on the if oscillation It was possible to track an ultra stable $1.365 \mathrm{GHz}$ signal over $110 \mathrm{~dB}$ while altering the beam current. At $620 \mathrm{~A}$, the power detected at the sight window of the pulse transformer tank was $126 \mathrm{~kW}$ peak. An increase of beam current beyond 620 A produced no detectable increase in rf power. Fig. 2 shows the relation between beam current and signal strength.

The frequency of oscillation was insensitive to beam current or magnetic field, an indication that a high- $Q$ structure was present. Simulation of the gun cavity if

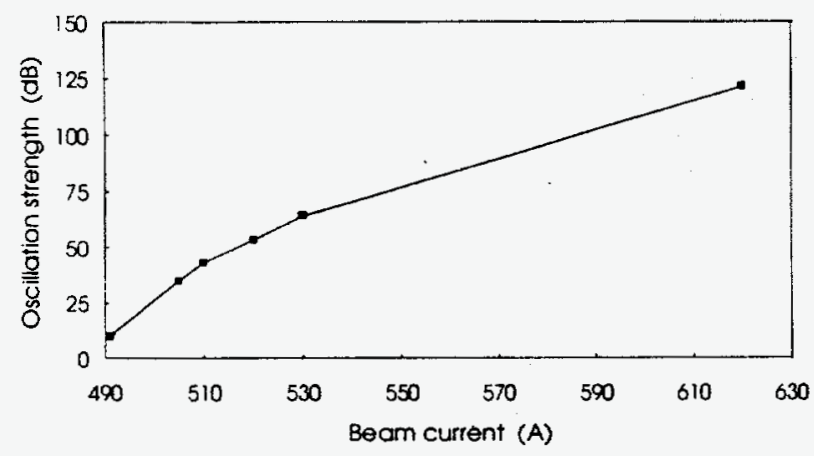

Fig. 2. Measurement of the $1.365 \mathrm{GHz}$ diode oscillation power versus beam current. Peak power remains constant above $620 \mathrm{~A}$.

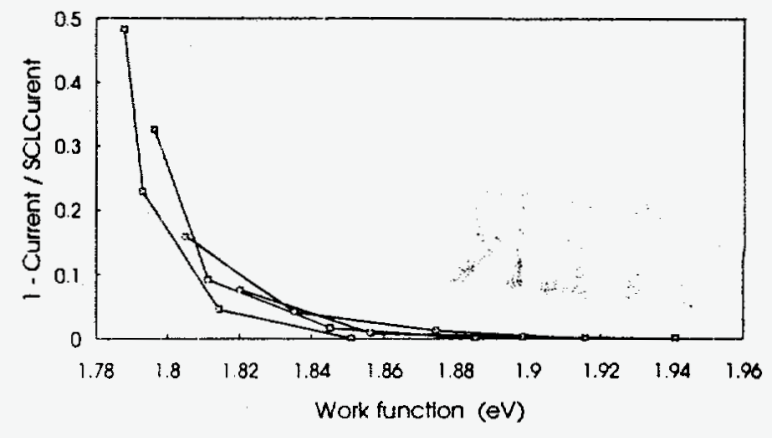

Fig. 3. Calculated work function of the diode cathode from measured data.

characteristics using SUPERFISH indicated a $1.381 \mathrm{GHz}$ mode inside the focus electrode, and a particle-in-cell simulation using MAFIA verified an increase in mode energy with a dependency on beam voltage (3). An autopsy performed on the diode appeared to verify the identification of the rf oscillation mechanism.

One method of analyzing gun performance and monitoring the degradation of a cathode is to plot a practical work function distribution (4). Plots of current versus cathode temperature at constant beam voltages can indicate the severity of electrode movement and the emission properties of a cathode. Common solutions between the data and the Richardson-Dushman equation of temperaturelimited emission current were found and the data was plotted as shown in Fig. 3. The peak of the curve coincides quite well with the $\sim 1.78 \mathrm{eV}$ work function of an osmium-coated cathode.

\section{0-MW Klystron}

\section{A. Klystron Design}

After discovery of the diode if gun oscillation, two changes were made to the klystron gun design. The gap suspected of coupling the $1.365 \mathrm{GHz}$ oscillation to the beam was shorted, and small strips of moly were fabricated to short out another possible source of oscillation at the cathode heat shield gap.

The collector diameter is 5 inches to reduce the incident power density and trap reflected electrons. A slanting hole was also drilled at the tip to reduce the possibility that axistraveling electrons would scatter back down the axis. The final collector dimensions were guided by using DC and $\mathrm{rf}$ bunched beams simulated from EGUN and a 2-1/2D particle-in-cell (PIC) code known as CONDOR (5). An electron scattering code was employed for final estimates of the power density and to determine the collector length.

Interaction cavities were designed by using $1 \mathrm{D}, 2 \mathrm{D}$, and $2-1 / 2 D$ codes. The $1 D$ code was used for first cut synthesis and analysis, while the $2 \mathrm{D}$ code was useful for large 


\section{DISCLAIMER}

This report was prepared as an account of work sponsored by an agency of the United States Government. Neither the United States Government nor any agency thereof, nor any of their employees, make any warranty, express or implied, or assumes any legal liability or responsibility for the accuracy, completeness, or usefulness of any information, apparatus, product, or process disclosed, or represents that its use would not infringe privately owned rights. Reference herein to any specific commercial product, process, or service by trade name, trademark, manufacturer, or otherwise does not necessarily constitute or imply its endorsement, recommendation, or favoring by the United States Government or any agency thereof. The views and opinions of authors expressed herein do not necessarily state or reflect those of the United States Government or any agency thereof. 


\section{DISCLAIMER}

Portions of this document may be illegible in electronic image products. Images are produced from the best available original document. 


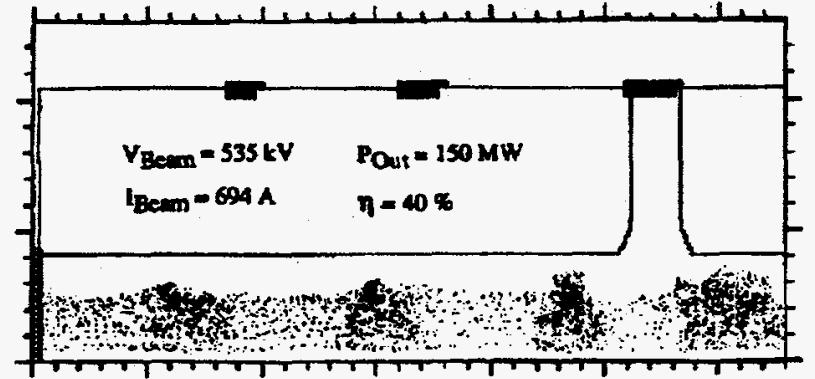

Fig. 4. 2-1/2D simulation using CONDOR showing electron bunches before and after the output cavity. Current interception is approximately $6 \%$.

parameter variation studies but gave inflated values of output power and efficiency. The CONDOR code performed the bulk of the work in fine tuning the cavity placement and frequencies. Using an iterative process, the first six nonfundamental modes in the if cavities were staggered to reduce the possibility of self-oscillation. Fig. 4 shows a simulation of the beam near the output cavity. Information regarding the momentum of each particle was also available and indicated that there would be no reflected electrons due to deceleration of the beam.

The completed klystron stands 104 inches tall from the gun baseplate to collector tip and weighs approximately 600 pounds. The klystron, as shown in Fig. 5, is inserted into a $15 \mathrm{~kW}$ solenoid and dressed with 3 to 4 inches of lead. High voltage connections are accomplished by means of gold plated spring-loaded "fuzz buttons" at the gun baseplate inside the pulse transformer tank.

\section{B. Klystron Experimental Results}

The klystron was processed at $3 \mu$ sf up to $150 \mathrm{MW}$ (3.6 $\mu$ s beam pulse) and did not suffer from the rf gun oscillation present in the diode. At small signal levels, the output power and gain peaked at $3.010 \mathrm{GHz}$. As the tube approached saturation, the optimum frequency dropped so that at $150 \mathrm{MW}$ the optimum frequency had fallen to $3.002 \mathrm{GHz}$. The agreement between simulation and performance was quite exceptional as can be seen in Table 3 .

While operating at $3 \mu$ s and certain combinations of magnetic field and beam voltage, an $\mathrm{rf}$ oscillation would appear at the falling edge of the pulse which, if left unchecked by not adjusting the magnetic field, lead to beam interception and gas formation. The frequencies of the oscillation were found to be $8.588 \mathrm{GHz}$ and the second harmonic at $17.18 \mathrm{GHz}$. The oscillations were detected at the input rf coupler, the output if coupler, and inside the pulse transformer tank thereby indicating that the signals were propagating within the drift tube. Adjustment of magnetic fields or operating voltage would not effect the frequency of oscillation, indicating that a resonant structure

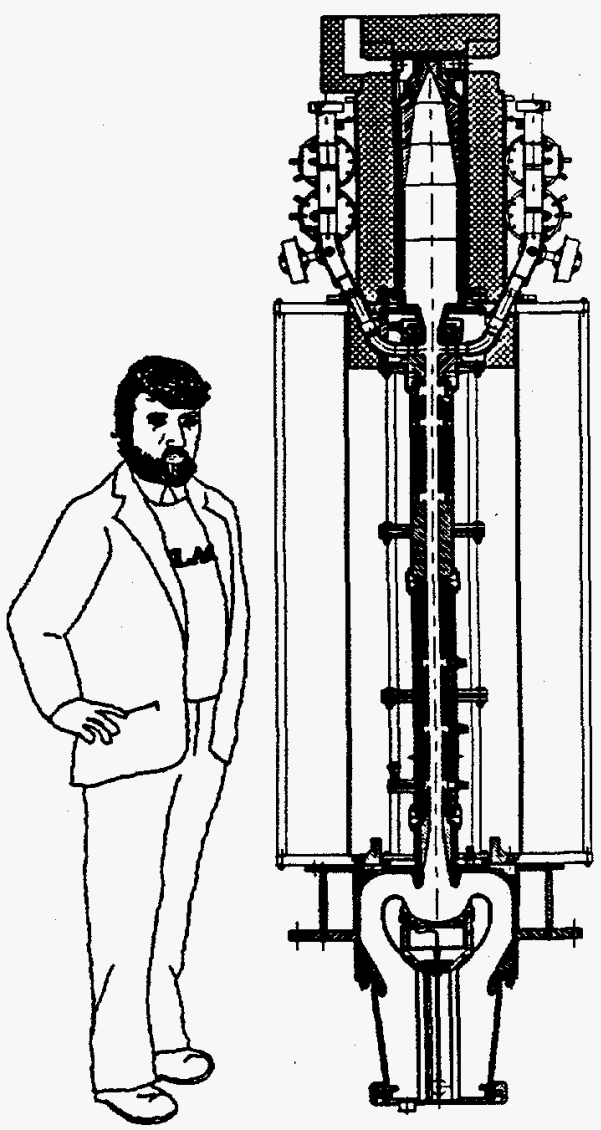

Fig. 5. The 150-MW klystron assembly shown with magnets and lead.

Table 3

Comparison of simulation versus experiment for the 150-MW klystron, (measured Pout, efficiency and gain are taken at $2.998 \mathrm{GHz}$ ).

\begin{tabular}{|l|c|c|}
\hline Item & Simulation & Experiment \\
\hline Pout & $154 \mathrm{MW}$ & $>150 \mathrm{MW}$ \\
\hline Efficiency & $40 \%$ & $41 \%-45 \%$ \\
\hline Saturated gain & $63 \mathrm{~dB}$ & $-54 \mathrm{~dB}$ \\
\hline Center frequency & $2.998 \mathrm{GHz}$ & $-3.002 \mathrm{GHz}$ \\
\hline
\end{tabular}

was present. The mode amplitude was found to be periodic with the magnetic field in the buncher, but not dependent on the gun coil or the output cavity coil settings. Areas of oscillation are plotted in Fig. 6 which shows measured edges of oscillation-free operation in solid tic marks. The "cones" which expand upward and to the right are areas at which the oscillation occured, weaker at the edges of the cones and stronger in the center of the cones.

Areas of tube stability generally increased when the cathode was operated slightly temperature-limited. Since operating in such a fashion is considered detrimental to an M-type cathode, the second klystron will use an uncoated 


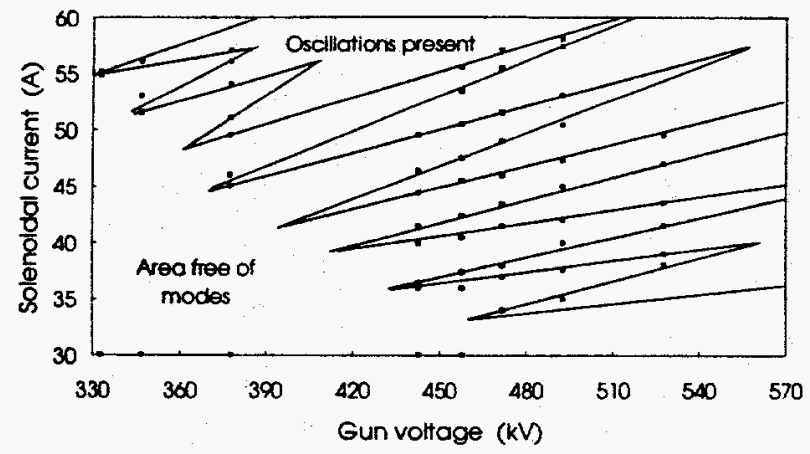

Fig. 6. Area of klystron self-oscillation at $3 \mu$ s operation. Coil current of 45 amps corresponds to an 1800 gauss axial field.

scandate cathode. Scandate cathodes are known to operate in the temperature-limited region for 40,000 hours or more in the $\mathbf{5 0 4 5}$ tubes and have an excellent track record.

Optimizing for $150 \mathrm{MW} @ 3 \mu \mathrm{s}$ operation at $524 \mathrm{kV}$, 1800 gauss, and a microperveance of 1.76 , no output pulse tearing or other instabilities were detected. Fig. 7 shows output power as a function of $\mathrm{ff}$ drive while the saturated output power as a function of beam voltage is plotted in Fig. 8. It is evident from the data that the tube is capable of more than $150 \mathrm{MW}$.

\section{Further Work}

The second 150-MW klystron is currently under final construction at SLAC. There are three differences between klystron \#2 and klystron \#1. To increase efficiency a 2-cell output cavity structure will be used instead of a single gap. For reasons outlined in the previous section, a scandate cathode will be used. Instead of copper drift tubes, two threaded and sandblasted stainless steel drift tubes will be

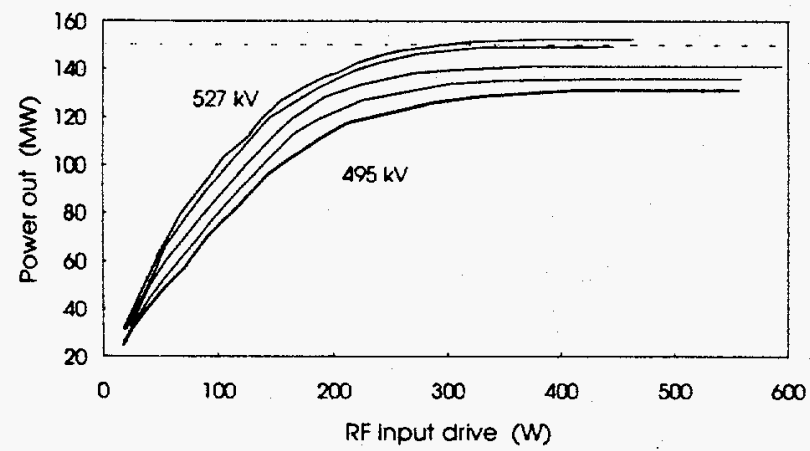

Fig. 7. Measured output power verses drive for the 150-MW klystron for 527 , $523,511,503$ and $495 \mathrm{kV}:(\mu \mathrm{K}=1.8, B z=1800 \mathrm{~g}, \tau=3 \mu \mathrm{s}$, Rep rate $=60 \mathrm{~Hz})$

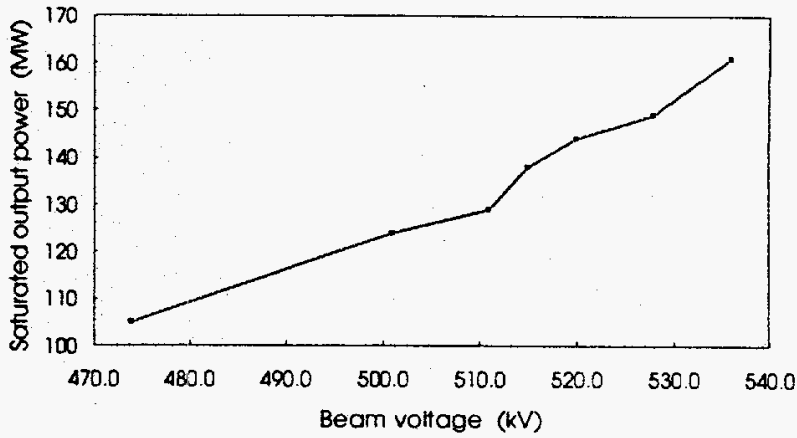

Fig. 8. Measured saturated output power ( $3 \mu \mathrm{sf}, 60 \mathrm{~Hz}$ ). Severe changes in slope are due to gain variation with magnetic field

inserted between cavities 3 and 4 , and 4 and 5 . This should increase the attenuation of of modes traveling in the drift tube and thereby reduce the coupling between the three cavities. The added loss should either eliminate the oscillations shown in Fig. 6 altogether, or increase the threshold of oscillation and allow for more stable operation. Testing of klystron \#2 is scheduled to begin late in 1994.

\section{Acknowledgments}

This work is sponsored by Deutsches Elektronen Synchrotron in Hamburg, Germany as part of a collaboration towards development of future colliders, and is supported by the Department of Energy under Contract DE-AC0376SF00515. Thanks go to Saul Gold and Ron Koontz for their work on the modulator, Mike Harding and Eric Jongewaard for mechanical design, Bernd Krietenstein for his MAFIA simulations, Erling Lien and George Miram for their work on the buncher, gun and many informative discussions. Discussions with Ken Eppley, Randy Fowkes and Ed Wright are gratefully acknowledged.

\section{References}

(1) K. Halbach, "Application of conformal mapping to evaluation and design of magnets containing iron with nonlinear $\mathrm{B}(\mathrm{H})$ characteristics," Nucl. Instr. and Meth., 64, pp. 278-284, 1968

(2) W. B. Hermannsfeldt, "Electron trajectory program," SLAC 226, Stanford Linear Acceleralor Center, Nov. 1979.

(3) K. Halbach and R. F. Holsinger, "SUPERFISH-A computer program for evaluation of if cavities with cylindrical symmetry," Particle Accelerators. Vol. 7, pp. 213-222, 1976.

(4) M. J. Cattelino and G. V. Miram, "Practical work function distributions: a diagnostic method for fingerprinting cathode quality," unpublished.

(5) B. Aimonetti, S. Brandon, K. Dyer, J. Moura, D. Nielsen Jr., "CONDOR user's guide," Livermore Computing Systems Document. Lawrence Livermore Nat'l Lab., April 1988. 